\title{
Stability of antioxidant vitamins in commercial vitamin supplements
}

\author{
Lucile Tiemi Abe-Matsumoto,2*, Geni Rodrigues Sampaio ${ }^{1}$, Deborah Helena Markowicz Bastos ${ }^{1}$ \\ ${ }^{1}$ Nutrition Department, School of Public Health, University of São Paulo, São Paulo, Brazil, ${ }^{2}$ Physical, Chemical and Sensory \\ Department, Food Center, Adolfo Lutz Institute, São Paulo, Brazil
}

\begin{abstract}
The stability of vitamins A, E, and C was determined in 12 brands of vitamin supplements over a 12-month storage period. The variations in concentrations of these vitamins across three different batches of five brands were measured. Vitamins A and E was determined by HPLC method, and vitamin C was measured by using potentiometric titration. All samples for stability studies were maintained at room temperature and protected from light. Measurements were carried out in the first semester of the expiration date and then every six months up to 12 months of storage. After this period, only one sample showed no significant decrease in vitamin $\mathrm{A}$ and $\mathrm{E}$ concentrations in relation to the concentrations measured at the beginning of the study. The concentration of vitamin $\mathrm{C}$ showed no significant decrease in $50 \%$ of the samples after 6 months of storage, although after 12 months, 92\% had significant losses in concentration. The analysis of the different batches showed significant variations in the vitamin levels, which do not seem to be significant for inspection purposes considering the tolerance outlined in the legislation. Overfortification of vitamin supplements during manufacture seems to be required, but the additional amount of supplementation will depend on each sample.
\end{abstract}

Keywords: Supplements/stability. Vitamins A, E, C/concentration.

\section{INTRODUCTION}

Vitamin and mineral supplements are defined as foods that supplement required nutrients in the daily diet of a healthy person when their dietary intake is insufficient. Supplements should contain a minimum of $25 \%$, up to a maximum of $100 \%$, of the Daily Recommended Intake (DRI) of vitamins and minerals in the daily portions indicated by the manufacturer, and cannot replace food or be considered an exclusive diet (Brasil, 1998).

As with any food products, the labeling of supplements must state the shelf life expiration date up to which the effectiveness of the product is guaranteed by the manufacturer (Brasil, 1998). The shelf life expiration date for food is regulated by Resolution RDC n. 259/2002 of the Brazillian Health Regulatory Agency (ANVISA), and the rules adopted in this resolution are covered by the Codex Alimentarius (Codex, 1991) and harmonized with recommendations of the Southern Common Market (Brasil, 2002; Mercosul, 2003).

\footnotetext{
*Correspondence: L. T. Abe-Matsumoto. Núcleo de Química, Física e Sensorial, Centro de Alimentos, Instituto Adolfo Lutz. Av. Dr. Arnaldo, 355, CEP 01246-000, São Paulo, SP, Brazil. Tel: 55-11-3068-2939. E-mail: lucile.matsumoto@ial.sp.gov.br
}

It is necessary to know the stability of vitamins to determine shelf life and ensure that the vitamin concentrations comply with those declared on the label until the end of the expiration date, and to meet the needs of the consumer. A multivitamin supplement may contain up to 13 vitamins. However, some vitamins are more stable than others, and the rate of degradation under specific conditions may vary from one vitamin to another (IADSA, 2014).

Several physical and chemical factors can affect the stability of vitamins. The major factors are temperature, humidity, presence of oxygen, light, $\mathrm{pH}$, oxidizing and reducing agents, presence of metal ions and other ingredients in the matrix, or the combination of several of these factors (IADSA, 2014).

The International Conference on Harmonization (ICH) establishes a stability testing to provide evidence on how the quality of a drug varies with time under the influence of a variety of environmental factors, establish a shelf life for the drug product, and recommend storage conditions, which are required for the registration of pharmaceuticals for human use (ICH, 2003). Pharmaceutical industries are likely to perform such tests on vitamin supplements, however, not all of them are 
manufactured by pharmaceutical industries. Therefore it is not known if all the supplement manufacturers follow the criteria of stability testing, since vitamin supplements are exempt from registration with the Ministry of Health (Brasil, 2010).

The Ministry of Health Ordinance n. 32/1998 allows over-fortification of vitamins and minerals in supplements to guarantee the specified dosage on the labeling until the expiration date, provided that the over-fortification is technically justified (Brasil, 1998). It is not known, however, whether vitamins remain stable in these matrixes during storage, or whether manufacturers practice overfortification to prevent degradation, as, to the best of our knowledge, there are no studies in current literature on the stability of vitamins concentrations in vitamin supplements marketed in Brazil.

The objectives of this study were to evaluate the stability of vitamins A, E, and C during 12 months of storage, and to measure variations in the levels of these vitamins in several batches of different vitamin supplements brands.

\section{MATERIAL AND METHODS}

\section{Samples}

For the stability testing, twelve brands of commercially available vitamin supplements in the form of tablets, dragees, hard capsules, soft gelatin capsules, and suspensions on the first six months of their shelf life period were randomly obtained from Sao Paulo retailers in 2014. The samples were selected according to several criteria: different matrixes; various sources of vitamin A; showed vitamin levels above, below, and close to the values declared on the label in the preliminary analysis; national and imported samples. Each supplement brand was identified sequentially as sample 1 through 12, and for each brand three packs of the same batch were purchased (Table I). For the examination of variations between batches, three different batches of five brands of vitamin supplements were purchased. These samples were selected with the purpose of evaluating the different supplements forms available in the market: tablet, hard-capsule, soft gelatin capsule, and suspension. Each of the brands was identified by letters A, B, C, D, and E, and each batch was identified as I, II, and III (Table I).

\section{Standards and reagents}

DL- $\alpha$-tocopheryl acetate, synthetic $\beta$-carotene, retinyl palmitate, retinyl acetate and L-ascorbic acid were purchased from Sigma-Aldrich (St Louis, USA); analytical grade reagents hydrochloric acid $(\mathrm{HCl})$, potassium iodide (KI) and potassium iodate $\left(\mathrm{KIO}_{3}\right)$ were purchased from Synth (Sao Paulo, Brazil); butyl hydroxy toluene (BHT) and triethylamine were from Sigma-Aldrich (St Louis, USA); sulfuric acid $\left(\mathrm{H}_{2} \mathrm{SO}_{4}\right)$ and metaphosphoric acid were from Merck (Darmstadt, Germany); HPLC grade reagents hexane, ethanol, and methanol were from Carlo Erba (Milan, Italy).

TABLE I - Characteristics of the vitamin supplements evaluated in the stability testing and the examination of batches and brands variations

\begin{tabular}{ccccc}
\hline $\begin{array}{c}\text { Stability test } \\
\text { samples }\end{array}$ & $\begin{array}{c}\text { Batches and brands } \\
\text { test samples }\end{array}$ & Country of origin & Presentation form & Source of vitamin A \\
\hline 1 & A & Canada & tablets & retinyl acetate and $\beta$-carotene \\
2 & B & Argentina & tablets & $\beta$-carotene \\
3 & - & Germany & tablets & - \\
4 & C & Brazil & hard-capsule & retinyl acetate \\
5 & - & Brazil & dragee & retinyl acetate \\
6 & - & Brazil & dragee & retinyl acetate \\
7 & - & Brazil & soft gelatin capsule & retinyl palmitate \\
8 & - & Brazil & soft gelatin capsule & retinyl palmitate \\
9 & D & Brazil & soft gelatin capsule & $\beta$-carotene \\
10 & - & Brazil & soft gelatin capsule & retinyl acetate \\
11 & - & Brazil & suspension & retinyl palmitate \\
12 & E & Brazil & suspension & retinyl palmitate \\
\hline
\end{tabular}




\section{Stability testing}

Samples were stored at room temperature (18-30 ${ }^{\circ} \mathrm{C}$ ) to simulate household consumption, away from light, and each package was opened at the time of analysis. Quantitative measurement of vitamins A, E, and C was performed at the time samples were obtained (Time 0 ) and every 6 months until completing 12 months of storage, according to the following design:

\begin{tabular}{|c|c|c|c|}
\hline $\begin{array}{c}\text { Shelf life } \\
\text { period }\end{array}$ & $1^{\circ}$ semester & $2^{\circ}$ semester & $3^{\circ}$ semester \\
\hline $\begin{array}{c}\text { Storage time in } \\
\text { the laboratory }\end{array}$ & $\begin{array}{c}0 \\
\text { (Time 0) }\end{array}$ & $\begin{array}{c}6 \text { months } \\
\text { (Time 6) }\end{array}$ & $\begin{array}{c}12 \text { months } \\
\text { (Time 12) }\end{array}$ \\
\hline $\begin{array}{c}\text { Evaluated } \\
\text { period }\end{array}$ & \multicolumn{3}{|c|}{12 months of storage } \\
\hline
\end{tabular}

Determination of retinyl acetate, retinyl palmitate, $\alpha$-tocopheryl acetate, and $\beta$-carotene

The fat-soluble vitamins were measured by highperformance liquid chromatography coupled with a diode array detector (HPLC-DAD) method previously reported (Abe-Matsumoto, Sampaio, Bastos, 2016). Extraction of vitamins: Approximately $250 \mathrm{mg}$ of pulverized sample was weighed using an analytical balance (Mettler Toledo, Schwerzenbach, $\mathrm{CH}$ ) and mixed with $1 \mathrm{~mL} 0.1 \mathrm{M} \mathrm{HCl}$ solution in $50 \mathrm{ml}$ polypropylene tubes with screw caps. The samples were sonicated in an ultrasonic bath (Unique, Sao Paulo, BR) for $15 \mathrm{~min}$. Vitamins were extracted in three steps using 10,10 , and $5 \mathrm{ml}$ of hexane, respectively, for the first, second, and third extractions. After each addition of hexane, the tubes were vortexed for $1 \mathrm{~min}$, placed in an ultrasonic bath for $5 \mathrm{~min}$, vortexed again for $30 \mathrm{~s}$, and centrifuged at $10,000 \mathrm{rpm}$ for $15 \mathrm{~min}$ at $4{ }^{\circ} \mathrm{C}$ (Sigma, Osterode, DE). After each round of centrifugation, the extracts were transferred to $25 \mathrm{~mL}$ amber volumetric flasks, and the final volume was completed with hexane. After agitating to ensure proper mixing, $3 \mathrm{~mL}$ aliquots were vacuum evaporated for $10 \mathrm{~min}$ at $40{ }^{\circ} \mathrm{C}$ on a CentriVap concentrator (Labconco, Kansas City, USA). The samples were reconstituted with $2 \mathrm{~mL}$ of ethanol containing 0.3 $\mathrm{mg} / \mathrm{mL}$ BHT, filtered through a $0.45 \mu \mathrm{m}$ membrane into amber vials, and injected into the HPLC system. For the analysis of the oily matrix, an amount between 150 and $400 \mathrm{mg}$ was weighed, and for analysis of liquid matrix, a volume between 1 and $3 \mathrm{~mL}$ was pipetted, depending on the concentration of vitamins declared in the nutritional information. The extraction of vitamins $\mathrm{A}$ and $\mathrm{E}$ and $\beta$-carotene was performed following the same procedure used for the powdered matrix, excluding the first two steps: $\mathrm{HCl}$ addition and ultrasonication for $15 \mathrm{~min}$.

Vitamin A content was expressed as $\mu \mathrm{g}$ RE (retinol equivalents) per serving using the following factors: $0.872,0.546$, and 0.167 , respectively, for retinyl acetate, retinyl palmitate, and $\beta$-carotene. Vitamin $\mathrm{E}$ content was expressed as mg $\alpha$-TE ( $\alpha$-tocopherol equivalents) per serving using the factor 0.91 for $\alpha$-tocopheryl acetate (USP, 2009). A serving portion refers to the daily intake recommended by the supplement manufacturer.

\section{Determination of ascorbic acid}

Vitamin $\mathrm{C}$ content was determined by iodometric titration using an automatic potentiometric titrator Titrando 901 (Metrohm Pensalab, Herisau, $\mathrm{CH}$ ) with a platinum ring electrode controlled by Tiamo ${ }^{\circledR}$ software (Ial, 2008). An amount between 200 and $600 \mathrm{mg}$ of the powdered sample was weighed in a $150-\mathrm{mL}$ beaker. To prepare the oily matrixes, $150-500 \mathrm{mg}$ of the sample was weighed in $50 \mathrm{~mL}$ polypropylene tubes, and mixed with $5 \mathrm{~mL}$ of $5 \%$ metaphosphoric acid and $5 \mathrm{~mL}$ of hexane, and then vortexed for $1 \mathrm{~min}$. Aliquots of the aqueous phase were pipetted into a $150-\mathrm{mL}$ beaker for titration. To prepare the liquid matrixes, $2-5 \mathrm{~mL}$ of sample was pipetted to a $150-\mathrm{mL}$ beaker and mixed with $10 \mathrm{~mL}$ of $20 \% \mathrm{H}_{2} \mathrm{SO}_{4}$ solution, $90 \mathrm{~mL}$ of distilled water, and $1 \mathrm{~mL}$ $10 \% \mathrm{KI}$ solution were added to the beakers. After $30 \mathrm{~s}$ of homogenization with a magnetic stirrer, the sample was titrated with $0.002 \mathrm{M} \mathrm{KIO}_{3}$ solution in an automatic titrator. The results were expressed as $\mathrm{mg}$ of vitamin $\mathrm{C}$ per serving.

\section{Statistical analysis}

The one-way analysis of variance (ANOVA) and Tukey's multiple comparisons test were used for each storage time $(0,6$, and 12 months $)$, and the correlation analysis was performed using Pearson's test. All statistical analyses were conducted using Microsoft Office Excel (2010) and Action software (Estatcamp, 2014). The level of statistical significance was set at $5 \%$ for all analyses.

\section{RESULTS AND DISCUSSION}

\section{Stability of vitamins A, E, and C}

Among the twelve samples selected for the study, only one (sample 3 ) did not contain vitamin A in its composition. Vitamin A concentrations at Time 0 and after 6 months of storage did not show significant differences 
in $64 \%$ of the samples. In the other samples, degradations between 15 and 34\% were measured. After 12 months of storage, only one sample (7) had no significant degradation in vitamin A concentration compared to the value determined at Time 0 , and the greatest loss $(66 \%)$ was observed in a hard-capsule supplement (sample 4). When checking the vitamin A concentration declared in the nutritional information labeling, five samples showed concentrations ranging from $47 \%$ to $81 \%$ below the values declared on the label at Time 0 . After 12 months of storage, one sample had a vitamin A concentration $89 \%$ below that stated on its label. The lack of strict regulations regarding the commercialization of vitamin supplements may explain the discrepancy between the values declared on the label and the actual values obtained by analysis. Vitamin supplements are exempt from registration in the Brazilian Ministry of Health, which facilitates the marketing of these products, and this discrepancy is an evidence of the lack of control by the manufacturers. Three samples (1,2 and 9) showed vitamin A contents above the declared value at Time 0 , although significant degradations were also observed in the 12th months of storage, approximating the values declared on their labels.

The sources of vitamin A quantified in the supplements were $\beta$-carotene, retinyl acetate, or retinyl palmitate. The three samples containing $\beta$-carotene (samples 1,2 and 9) had vitamin A concentrations above the declared values at Time 0 . Moreover, even after up to $40 \%$ degradation after 12 months of storage, each sample still maintained a concentration 3-22\% higher, which was closer to the declared values. In these cases, the manufacturer probably practiced over-fortification, predicting the degradation of the vitamin.

In the two liquid samples containing retinyl palmitate (samples 11 and 12) analyzed in this study, the contents of vitamin A were above the declared values, which are within the tolerance of $20 \%$ variability provided in the regulatory legislation. However, after 12 months of storage, $57 \%$ degradation occurred in one sample, which corresponded to $54 \%$ less than the declared value. The other liquid sample showed a $20 \%$ loss, and even after 12 months of storage, its content remained within the tolerance range of $20 \%$. It was verified that samples of the same matrix and the same source of vitamin A may present different rates of degradation, probably due to the formulation of the product. One sample contained acidity regulators as an excipient, which may impair or promote the stability of the vitamins depending on the $\mathrm{pH}$ of the medium. The presence of minerals and hygroscopic ingredients, such as sorbitol and glycerol, also influence the stability of vitamins (IADSA, 2014).
Since vitamin A (retinoids and carotenoids) is a group of unsaturated hydrocarbons, its degradation generally follows the same pathway of degradation as unsaturated lipids. Losses of vitamin A activity occurs when the side chain of unsaturated isoprenoids is affected, such as by auto oxidation or geometric isomerization. Exposure to light, acids, chlorinated solvents, and high temperature can induce isomerization, and consequently, loss of vitamin A activity (Gregory, 2007).

The stability of vitamin E was evaluated in eight samples, since the other samples did not contain vitamin E. There were no significant degradations of vitamin $E$ in three samples after 6 months of storage, while in the others the loss ranged from 8 to $32 \%$. After 12 months, negative variations between $9-59 \%$ were observed, except in one hard-capsule supplement (sample 4), in which no significant variation was observed. The highest percentage of degradation at both 6 months and 12 months of storage was found in a suspension supplement (sample 11).

Three samples contained vitamin E contents above the declared values on the label, which remained unchanged after 12 months of storage, despite the significant degradation observed. Sample 1 contained $60 \%$ more vitamin $\mathrm{E}$ of the declared content, but underwent degradation of $11 \%$ after 6 months and $20 \%$ after 12 months. Assuming a 10\% loss for each storage period (6 months), this sample would still be close to the declared value on the expiration date $(7$ months remaining). However, the rate of degradation is not the same, nor constant for all samples. The liquid supplement (sample 11), for example, showed $32 \%$ degradation after 6 months, and almost twice this value after 12 months of storage. Thus, the content of vitamin E at T0 was $36 \%$ above the declared content, but with 12 months of storage it was reduced to $44 \%$ below the declared value. For the other samples, no degradation rates were observed at 6 and at 12 months of storage.

Tocopherol acts as an antioxidant, neutralizing free radicals by donating electrons to them. Similar to vitamin A, vitamin E undergoes oxidative degradation strongly influenced by factors that affect lipid oxidation, such as the presence of oxygen and free radicals. The $\alpha$-tocopheryl acetate and other esters with vitamin E activity do not participate in free radical scavenging activity and are subject to less oxidative degradation than non-esterified compounds (Gregory, 2007). This ester compound is commonly used in the composition of vitamin supplements as a source of vitamin E. Thus, it was expected that vitamin E would be more stable than vitamin A in supplements, even though significant degradations were observed in 
some samples in the present study and in other matrixes in other studies (Haro-Vicente et al., 2013; Tavcar-Kalcher, Vengust, 2007; Melo, Almeida-Muradian, 2010).

A lower percentage of degradation was observed to vitamin $\mathrm{C}$ in relation to vitamins $\mathrm{A}$ and $\mathrm{E}$. No significant degradation of vitamin $\mathrm{C}$ was observed in $50 \%$ of the samples after 6 months of storage; however, after 12 months, only one sample exhibited an unchanged concentration of this vitamin. Although solid supplements tend to be more stable than liquids, a greater degradation of vitamin C was observed in a dragee sample (19\%). In relation to the declared values on the labeling, only one sample presented a value outside the $20 \%$ tolerance range at $\mathrm{T} 0$. This concentration was above the declared value, which was maintained after 12 months of storage.

Chemical degradation of vitamin $\mathrm{C}$ involves its oxidation to form dehydroascorbic acid (DHAA), followed by its hydrolysis to 2,3-diketogulonic acid, and its subsequent oxidation, dehydration, and polymerization to other non-nutritional compounds. The main factors influencing the speed and mechanism of vitamin $\mathrm{C}$ degradation are $\mathrm{pH}$, oxygen concentration, and the presence of metal ions such as copper and iron (Gregory, 2007).

According to Ottaway (2008), multivitamin tablets stored in plastic packaging for 6 months at $25{ }^{\circ} \mathrm{C}$ and $75 \%$ humidity presented $44 \%$ and $23 \%$ losses of vitamins $\mathrm{A}$ and $\mathrm{C}$, respectively. In the present study, we observed that the percentage of degradation of vitamin $C$ was generally lower than that of vitamin A, despite vitamin C being more sensitive to degradation due to its oxidative susceptibility. There are no other data in the literature on vitamin degradation in commercial vitamin supplements, but studies in other products have also shown loss of vitamin content during storage. In enriched milk stored at $37^{\circ} \mathrm{C}$ for 9 months, $67 \%$ and $34 \%$ reductions in vitamin $\mathrm{A}$ and $\mathrm{E}$ content, respectively, had occurred. Premix samples stored at $25^{\circ} \mathrm{C}$ for 12 months under light showed decreases around $55 \%$ for vitamins A and E. Losses of up to $68 \%, 37 \%$, and $75 \%$, respectively of vitamins $C$, E, and $\beta$-carotene were observed in bee pollen samples after 12 months of storage at room temperature and exposure to light, and even after storage at $-60{ }^{\circ} \mathrm{C}$ for 12 months, 14 to $26 \%$ reduction in vitamin $\mathrm{C}$ content occurred in plant samples (Haro-Vicente et al., 2013; Tavcar-Kalcher, Vengust, 2007; Melo, Almeida-Muradian, 2010; Phillips et al., 2010).

No pattern was observed in the rates of vitamin degradation in the supplements analyzed in this study. According to the recommendations of the International Alliance of Dietary/Food Supplement Associations
(IADSA, 2014), the presentation form of the supplement may significantly affect the stability of the compounds. In a liquid supplement, for example, the molecules are free to react with each other; whereas the molecules in a solid supplement will be less likely to react chemically with one another. Further, the type of coating, such as hard capsule, soft gelatin capsules, or coated tablets, represents a protective barrier for factors affecting stability, such as moisture, light, and oxygen. In the present study, powdered matrixes (tablets, dragees, and hard capsules), oily matrixes (soft gelatin capsules), and liquid matrixes (suspensions) were analyzed, and vitamin degradations were observed in the three different matrixes (Figure 1).

The type of microencapsulation and particle size of the compounds may also affect stability, especially for molecules that are sensitive to light, moisture, and oxygen. Small particles have a larger surface area exposed to the environment, whereas larger particles have a smaller surface area, and are thus more stable (IADSA, 2014).

Some characteristics of packaging such as its thickness, degree of vapor permeability, and humidity, the use of desiccants inside the packaging, and inert atmosphere, such as nitrogen gas inside the storage container, can also alter the stability of vitamins (IADSA, 2014). The samples evaluated in this study were contained in plastic bottles composed of high-density polyethylene or in blister packs.

Most vitamins did not show constant degradation rates at 6 months and 12 months of storage, and it is not possible to predict their concentration at the expiration date. Samples with over-fortification of vitamins were observed during storage for 6 months and 12 months, which, although suffering significant degradation, were kept in conformity with the values declared on the labels. This behavior, however, was not observed for all the samples analyzed. Regarding vitamins A and E, about $40 \%$ of the samples evaluated had levels below that declared during the first six months of storage, indicating the lack of quality control of these products.

After 12 months of storage, most of the samples had a content below the declared value for vitamin $\mathrm{A}$, and levels very close to those declared for vitamin C. After this period, all the samples had a period of 7 to 10 months from their respective expiration dates, with the exception of a liquid sample (12) that was one month from the expiration date. Considering the observed degradations, the need for over-fortification of the vitamins evaluated in the supplements of our study was verified, as vitamin degradation will probably still occur until the expiration date of these products. 
TABLE II - Analysis of vitamin A ( $\mu \mathrm{g}$ RE/serving) in supplements during storage

\begin{tabular}{|c|c|c|c|c|c|}
\hline $\begin{array}{c}\text { Sample } \\
\text { (form) }\end{array}$ & Time (month) & Vitamin A & D (\%) & $\begin{array}{c}\text { Declared value } \\
\text { (Source of vit A) }\end{array}$ & $\mathrm{C}(\%)$ \\
\hline \multirow{3}{*}{$\begin{array}{c}1 \\
\text { (tablet) }\end{array}$} & 0 & $550,5 \pm 21.2^{\mathrm{a}}$ & - & \multirow{3}{*}{$\begin{array}{c}400 \\
\text { (Retinyl acetate and } \\
\beta \text {-carotene) }\end{array}$} & 37.6 \\
\hline & 6 & $557.6 \pm 15.1^{\mathrm{a}}$ & 0 & & 39.4 \\
\hline & 12 & $489.8 \pm 15.7^{b}$ & 12.1 & & 22.4 \\
\hline \multirow{3}{*}{$\begin{array}{c}2 \\
\text { (tablet) }\end{array}$} & 0 & $883.1 \pm 10.6^{\mathrm{a}}$ & - & \multirow{3}{*}{$\begin{array}{c}600 \\
(\beta \text {-carotene })\end{array}$} & 47.1 \\
\hline & 6 & $810.6 \pm 51.0^{\mathrm{a}}$ & 8.2 & & 35.1 \\
\hline & 12 & $694.6 \pm 58.5^{\mathrm{b}}$ & 21.3 & & 15.7 \\
\hline \multirow{3}{*}{$\begin{array}{c}4 \\
\text { (hard capsule) }\end{array}$} & 0 & $316.5 \pm 2.3^{\mathrm{a}}$ & - & \multirow{3}{*}{$\begin{array}{c}600 \\
\text { (Retinyl acetate) }\end{array}$} & -47.2 \\
\hline & 6 & $213.3 \pm 7.0^{\mathrm{b}}$ & 32.6 & & -64.4 \\
\hline & 12 & $107.8 \pm 11.1^{\mathrm{c}}$ & 65.9 & & -82.0 \\
\hline \multirow{3}{*}{$\begin{array}{c}5 \\
\text { (dragee) }\end{array}$} & 0 & $147.2 \pm 0.9^{\mathrm{a}}$ & - & \multirow{3}{*}{$\begin{array}{c}600 \\
\text { (Retinyl acetate) }\end{array}$} & -75.5 \\
\hline & 6 & $153.6 \pm 0.2^{\mathrm{a}}$ & 0 & & -74.4 \\
\hline & 12 & $114.2 \pm 0.6^{b}$ & 22.4 & & -81.0 \\
\hline \multirow{3}{*}{$\begin{array}{c}6 \\
\text { (dragee) }\end{array}$} & 0 & $124.0 \pm 4.6^{\mathrm{a}}$ & - & \multirow{3}{*}{$\begin{array}{c}600 \\
\text { (Retinyl acetate) }\end{array}$} & -79.3 \\
\hline & 6 & $81.3 \pm 2.7^{b}$ & 34.4 & & -86.4 \\
\hline & 12 & $66.2 \pm 4.8^{c}$ & 46.6 & & -89.0 \\
\hline \multirow{3}{*}{$\begin{array}{c}7 \\
\text { (gel caps) }\end{array}$} & 0 & $358.9 \pm 8.8^{\mathrm{a}}$ & - & \multirow{3}{*}{$\begin{array}{c}400 \\
\text { (Retinyl palmitate) }\end{array}$} & -10.3 \\
\hline & 6 & $337.1 \pm 16.5^{\mathrm{a}}$ & 6.1 & & -15.7 \\
\hline & 12 & $364.5 \pm 27.8^{\mathrm{a}}$ & 0 & & -8.9 \\
\hline \multirow{3}{*}{$\begin{array}{c}8 \\
\text { (gel caps) }\end{array}$} & 0 & $109.1 \pm 8.5^{\mathrm{a}}$ & - & \multirow{3}{*}{$\begin{array}{c}600 \\
\text { (Retinyl palmitate) }\end{array}$} & -81.8 \\
\hline & 6 & $109.9 \pm 5.5^{\mathrm{a}}$ & 0 & & -81.7 \\
\hline & 12 & $79.1 \pm 2.2^{\mathrm{b}}$ & 27.5 & & -86.8 \\
\hline \multirow{3}{*}{$\begin{array}{c}9 \\
\text { (gel caps) }\end{array}$} & 0 & $966.2 \pm 30.1^{\mathrm{a}}$ & - & \multirow{3}{*}{$\begin{array}{c}600 \\
(\beta \text {-carotene })\end{array}$} & 61.0 \\
\hline & 6 & $956.2 \pm 16.2^{\mathrm{a}}$ & 1.0 & & 59.4 \\
\hline & 12 & $579.7 \pm 25.8^{\mathrm{b}}$ & 40.0 & & 3.4 \\
\hline \multirow{3}{*}{$\begin{array}{c}10 \\
\text { (gel caps) }\end{array}$} & 0 & $187.3 \pm 1.8^{\mathrm{a}}$ & - & \multirow{3}{*}{$\begin{array}{c}600 \\
\text { (Retinyl acetate) }\end{array}$} & -68.8 \\
\hline & 6 & $187.3 \pm 2.7^{\mathrm{a}}$ & 0 & & -68.8 \\
\hline & 12 & $173.2 \pm 3.5^{\mathrm{b}}$ & 7.5 & & -71.1 \\
\hline \multirow{3}{*}{$\begin{array}{c}11 \\
\text { (suspension) }\end{array}$} & 0 & $242.6 \pm 2.5^{\mathrm{a}}$ & - & \multirow{3}{*}{$\begin{array}{c}225 \\
\text { (Retinyl palmitate) }\end{array}$} & 7.8 \\
\hline & 6 & $206.4 \pm 9.8^{\mathrm{b}}$ & 14.9 & & -8.3 \\
\hline & 12 & $103.8 \pm 5.3^{\mathrm{c}}$ & 57.2 & & -53.9 \\
\hline \multirow{3}{*}{$\begin{array}{c}12 \\
\text { (suspension) }\end{array}$} & 0 & $212.9 \pm 13.9^{a}$ & - & \multirow{3}{*}{$\begin{array}{c}200 \\
\text { (Retinyl palmitate) }\end{array}$} & 6.4 \\
\hline & 6 & $170.4 \pm 7.0^{\mathrm{b}}$ & 20.0 & & -14.8 \\
\hline & 12 & $167.8 \pm 6.6^{\mathrm{b}}$ & 21.2 & & -16.1 \\
\hline
\end{tabular}

Values of vitamin A are expressed as mean \pm standard deviation $(n=3)$. Different superscript letters in the same column and in the same sample indicate statistical difference $(\mathrm{p}<0.05)$, according to Tukey's Test. D $(\%)$ : Percentage of degradation with respect to the content analyzed at Time 0 . C (\%): Percentage of vitamin contents above or below the values declared on the label.

\section{Analyses of different batches of vitamin brands}

The determined amounts of vitamins A, E, and C in different batches and brands of vitamin supplements are shown in Figure 1. Regarding vitamins A, E, and C, respectively two, three and one sample did not present statistically significant differences between the three batches evaluated.

In each batch analyzed, each sample had a different time period prior to each expiration date (Table V). 
TABLE III - Analysis of vitamin E (mg $\alpha$-TE/serving) in supplements during storage

\begin{tabular}{|c|c|c|c|c|c|}
\hline $\begin{array}{c}\begin{array}{c}\text { Sample } \\
\text { (form) }\end{array} \\
\end{array}$ & $\begin{array}{c}\text { Time } \\
\text { (month) }\end{array}$ & Vitamin E & D (\%) & Declared Value & $\mathrm{C}(\%)$ \\
\hline \multirow{3}{*}{$\begin{array}{c}1 \\
\text { (tablet) }\end{array}$} & 0 & $10.7 \pm 0.5^{\mathrm{a}}$ & - & \multirow{3}{*}{6.7} & 59.7 \\
\hline & 6 & $9.5 \pm 0.1^{\mathrm{b}}$ & 11.2 & & 41.8 \\
\hline & 12 & $8.6 \pm 0.1^{\mathrm{c}}$ & 19.6 & & 28.4 \\
\hline \multirow{3}{*}{$\begin{array}{c}2 \\
\text { (tablet) }\end{array}$} & 0 & $16.1 \pm 0.3^{\mathrm{a}}$ & - & \multirow{3}{*}{10} & 61.0 \\
\hline & 6 & $15.2 \pm 0.4^{\mathrm{b}}$ & 5.6 & & 52.0 \\
\hline & 12 & $14.7 \pm 0.4^{\mathrm{b}}$ & 8.7 & & 47.0 \\
\hline \multirow{3}{*}{$\begin{array}{c}4 \\
\text { (hard capsule) }\end{array}$} & 0 & $7.8 \pm 0.8^{\mathrm{a}}$ & - & \multirow{3}{*}{10} & -22.0 \\
\hline & 6 & $6.9 \pm 0.6^{\mathrm{a}}$ & 11.5 & & -31.0 \\
\hline & 12 & $6.7 \pm 0.1^{\mathrm{a}}$ & 14.1 & & -33.0 \\
\hline \multirow{3}{*}{$\begin{array}{c}7 \\
\text { (gel caps) }\end{array}$} & 0 & $9.6 \pm 0.7^{\mathrm{ab}}$ & - & \multirow{3}{*}{6.7} & 43.3 \\
\hline & 6 & $10.8 \pm 0.7^{\mathrm{a}}$ & 0 & & 61.2 \\
\hline & 12 & $9.0 \pm 0.3^{\mathrm{b}}$ & 6.2 & & 34.3 \\
\hline \multirow{3}{*}{$\begin{array}{c}8 \\
\text { (gel caps) }\end{array}$} & 0 & $4.3 \pm 0.3^{\mathrm{a}}$ & - & \multirow{3}{*}{10} & -57.0 \\
\hline & 6 & $3.4 \pm 0.4^{\mathrm{b}}$ & 20.9 & & -66.0 \\
\hline & 12 & $3.5 \pm 0.1^{\mathrm{b}}$ & 18.6 & & -65.0 \\
\hline \multirow{3}{*}{$\begin{array}{c}9 \\
\text { (gel caps) }\end{array}$} & 0 & $10.9 \pm 0.2^{\mathrm{a}}$ & - & \multirow{3}{*}{10} & 9,0 \\
\hline & 6 & $11.2 \pm 0.3^{\mathrm{a}}$ & 0 & & 12.0 \\
\hline & 12 & $8.3 \pm 0.0^{\mathrm{b}}$ & 23.8 & & -17.0 \\
\hline \multirow{3}{*}{$\begin{array}{c}10 \\
\text { (gel caps) }\end{array}$} & 0 & $6.2 \pm 0.2^{\mathrm{a}}$ & - & \multirow{3}{*}{10} & -38.0 \\
\hline & 6 & $5.7 \pm 0.1^{b}$ & 8.1 & & -43.0 \\
\hline & 12 & $5.6 \pm 0.0^{\mathrm{b}}$ & 9.7 & & -44.0 \\
\hline \multirow{3}{*}{$\begin{array}{c}11 \\
\text { (suspension) }\end{array}$} & 0 & $3.4 \pm 0.0^{\mathrm{a}}$ & - & \multirow{3}{*}{2.5} & 36.0 \\
\hline & 6 & $2.3 \pm 0.1^{b}$ & 32.3 & & -8.0 \\
\hline & 12 & $1.4 \pm 0.0^{\mathrm{c}}$ & 58.8 & & -44.0 \\
\hline
\end{tabular}

Values of vitamin $E$ are expressed as mean \pm standard deviation $(n=3)$. Different superscript letters in the same column and in the same sample indicate statistical difference $(\mathrm{p}<0.05)$, according to Tukey's Test. D $(\%)$ : Percentage of degradation with respect to the content analyzed at Time 0 . C (\%): Percentage of vitamin contents above or below the values declared on the label.

Therefore, the correlation between the values of vitamins determined and the time in months remaining until expiration at the time of analysis was verified. Pearson's test showed correlations above 0.90 for vitamin A only in samples A and D and for vitamin E in sample D (Table VI).

It was expected to find correlations in these parameters, as the results of the stability study showed significant degradation of the vitamins following storage. However, the low correlation observed for most of the samples indicates that the variations observed may be due to other factors such as processing, lack of standardization, or even problems with homogenization of the components in the supplement. Considering the $20 \%$ tolerance for variability in vitamin concentrations outlined in the regulatory legislation, it was observed for most of the vitamins analyzed that, regardless of the variation observed between batches, when the first batch evaluated showed levels in compliance with the declared values, the other batches also presented levels within this range. The same conditions were observed in samples with contents above and below their declared values (Figure 1). In some samples, over-fortification of vitamins was observed, whereas in others not even the minimum declared quantity was found.

\section{CONCLUSIONS}

After 12 months of storage, significant degradation of vitamins A, E, and C occurred in approximately $90 \%$ of the samples evaluated in this study. Over-fortification 
TABLE IV - Analysis of vitamin C (mg/serving) in supplements during storage

\begin{tabular}{|c|c|c|c|c|c|}
\hline $\begin{array}{c}\text { Sample } \\
\text { (form) }\end{array}$ & $\begin{array}{c}\text { Time } \\
\text { (month) }\end{array}$ & Vitamin C & D (\%) & Declared value & $\mathrm{C}(\%)$ \\
\hline \multirow{3}{*}{$\begin{array}{c}1 \\
\text { (tablet) }\end{array}$} & 0 & $49.0 \pm 1.6^{\mathrm{a}}$ & - & \multirow{3}{*}{45} & 8.9 \\
\hline & 6 & $44.8 \pm 0.2^{b}$ & 8.6 & & -0.4 \\
\hline & 12 & $46.5 \pm 1.1^{\mathrm{ab}}$ & 5.10 & & 3.3 \\
\hline \multirow{3}{*}{$\begin{array}{c}2 \\
\text { (tablet) }\end{array}$} & 0 & $51.7 \pm 0.3^{\mathrm{a}}$ & - & \multirow{3}{*}{45} & 14.9 \\
\hline & 6 & $52.7 \pm 0.8^{\mathrm{a}}$ & 0 & & 17.1 \\
\hline & 12 & $47.8 \pm 0.7^{\mathrm{b}}$ & 7.5 & & 6.2 \\
\hline \multirow{3}{*}{$\begin{array}{c}3 \\
\text { (tablet) }\end{array}$} & 0 & $49.6 \pm 0.5^{\mathrm{a}}$ & - & \multirow{3}{*}{45} & 10.2 \\
\hline & 6 & $49.6 \pm 0.4^{\mathrm{a}}$ & 0 & & 10.2 \\
\hline & 12 & $41.4 \pm 0.7^{\mathrm{b}}$ & 16.5 & & -8.0 \\
\hline \multirow{3}{*}{$\begin{array}{c}4 \\
\text { (hard-capsule) }\end{array}$} & 0 & $44.4 \pm 1.4^{\mathrm{a}}$ & - & \multirow{3}{*}{45} & 1.3 \\
\hline & 6 & $44.7 \pm 2.0^{\mathrm{a}}$ & 0 & & -0.6 \\
\hline & 12 & $46.2 \pm 1.2^{\mathrm{a}}$ & 0 & & 2.7 \\
\hline \multirow{3}{*}{$\begin{array}{c}5 \\
\text { (dragee) }\end{array}$} & 0 & $46.0 \pm 0.4^{\mathrm{a}}$ & - & \multirow{3}{*}{45} & 2.2 \\
\hline & 6 & $40.5 \pm 0.4^{b}$ & 11.9 & & -10.0 \\
\hline & 12 & $39.5 \pm 1.4^{\mathrm{b}}$ & 14.1 & & -12.2 \\
\hline \multirow{3}{*}{$\begin{array}{c}6 \\
\text { (dragee) }\end{array}$} & 0 & $40.5 \pm 0.3^{\mathrm{a}}$ & - & \multirow{3}{*}{45} & -10.0 \\
\hline & 6 & $37.5 \pm 0.5^{\mathrm{b}}$ & 7.4 & & -16.7 \\
\hline & 12 & $32.9 \pm 0.5^{\mathrm{c}}$ & 18.8 & & -26.9 \\
\hline \multirow{3}{*}{$\begin{array}{c}7 \\
\text { (gel caps) }\end{array}$} & 0 & $68.7 \pm 1.1^{\mathrm{a}}$ & - & \multirow{3}{*}{45} & 52.7 \\
\hline & 6 & $65.8 \pm 1.6^{\mathrm{a}}$ & 4.2 & & 46.2 \\
\hline & 12 & $56.9 \pm 1.8^{\mathrm{b}}$ & 17.2 & & 26.4 \\
\hline \multirow{3}{*}{$\begin{array}{c}8 \\
\text { (gel caps) }\end{array}$} & 0 & $54.4 \pm 2.8^{\mathrm{a}}$ & - & \multirow{3}{*}{45} & 20.9 \\
\hline & 6 & $46.9 \pm 1.6^{\mathrm{b}}$ & 13.8 & & 4.2 \\
\hline & 12 & $45.0 \pm 0.8^{\mathrm{b}}$ & 17.3 & & 0 \\
\hline \multirow{3}{*}{$\begin{array}{c}9 \\
\text { (gel caps) }\end{array}$} & 0 & $46.1 \pm 0.4^{\mathrm{a}}$ & - & \multirow{3}{*}{45} & 2.4 \\
\hline & 6 & $48.1 \pm 1.4^{\mathrm{a}}$ & 0 & & 6.9 \\
\hline & 12 & $43.3 \pm 1.2^{\mathrm{b}}$ & 6.1 & & -3.8 \\
\hline \multirow{3}{*}{$\begin{array}{c}10 \\
\text { (gel caps) }\end{array}$} & 0 & $53.8 \pm 1.5^{\mathrm{a}}$ & - & \multirow{3}{*}{45} & 19.6 \\
\hline & 6 & $49.1 \pm 1.2^{\mathrm{b}}$ & 8.7 & & 9.1 \\
\hline & 12 & $46.9 \pm 0.2^{\mathrm{b}}$ & 12.8 & & 4.2 \\
\hline \multirow{3}{*}{$\begin{array}{c}11 \\
\text { (suspension) }\end{array}$} & 0 & $12.1 \pm 0.2^{\mathrm{a}}$ & - & \multirow{3}{*}{15} & -19.3 \\
\hline & 6 & $11.2 \pm 0.2^{\mathrm{b}}$ & 7.4 & & -25.3 \\
\hline & 12 & $10.9 \pm 0.4^{\mathrm{b}}$ & 9.9 & & -27.3 \\
\hline \multirow{3}{*}{$\begin{array}{c}12 \\
\text { (suspension) }\end{array}$} & 0 & $34.4 \pm 0.4^{\mathrm{a}}$ & - & \multirow{3}{*}{30} & 14.7 \\
\hline & 6 & $34.2 \pm 0.4^{\mathrm{a}}$ & 0.6 & & 14.0 \\
\hline & 12 & $31.9 \pm 1.2^{\mathrm{b}}$ & 7.3 & & 6.3 \\
\hline
\end{tabular}

Values of vitamin $C$ are expressed as mean \pm standard deviation $(n=3)$. Different superscript letters in the same column and in the same sample indicate statistical difference $(\mathrm{p}<0.05)$, according to Tukey's Test. D $(\%)$ : Percentage of degradation with respect to the content analyzed at Time 0 . C (\%): Percentage of vitamin contents above or below the values declared on the label. 
Vitamin A

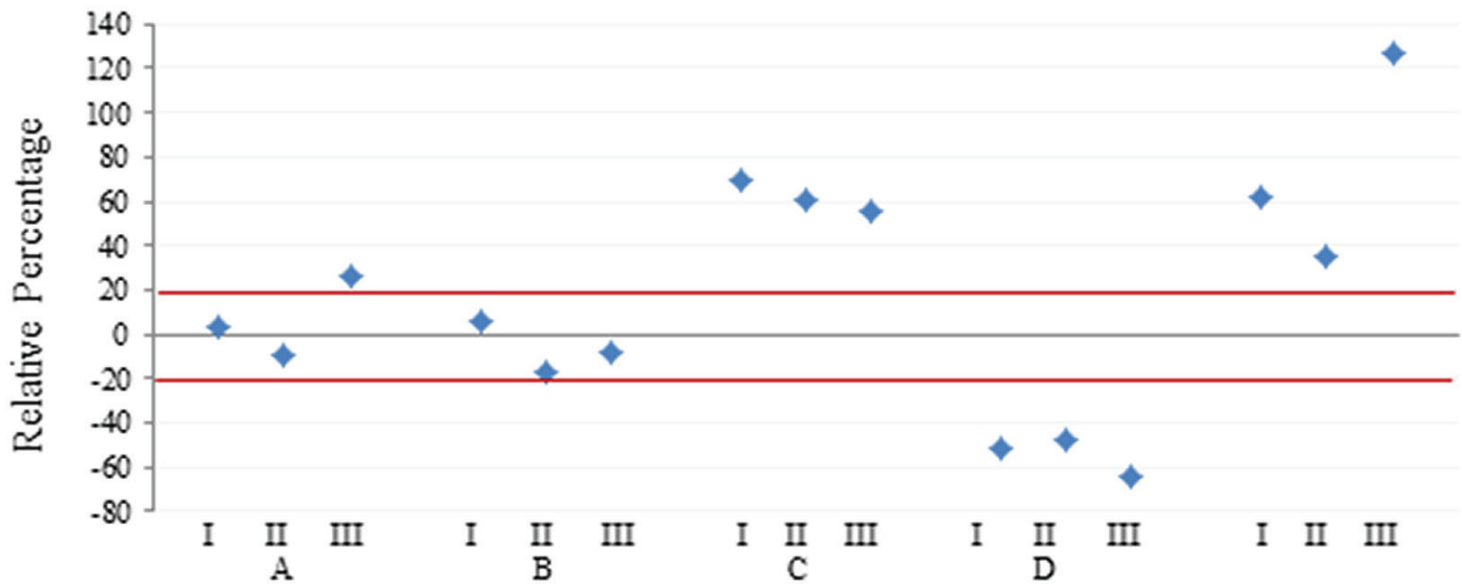

Samples

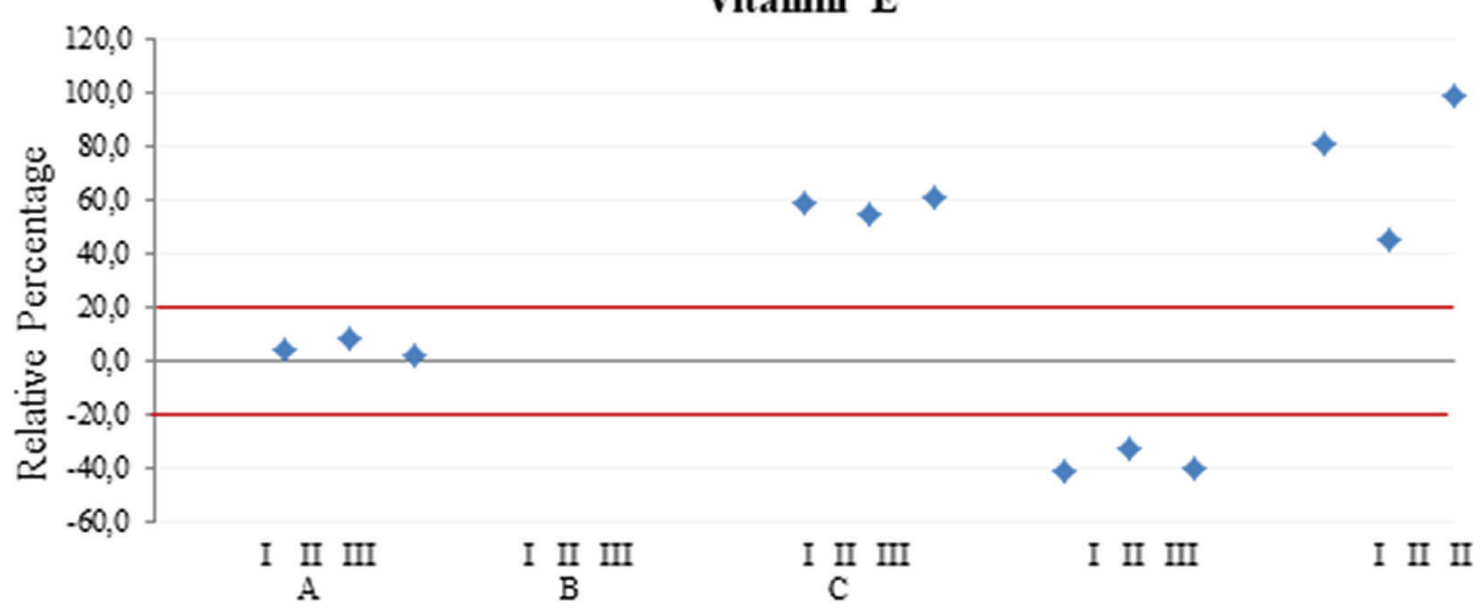

Samples

Vitamin C

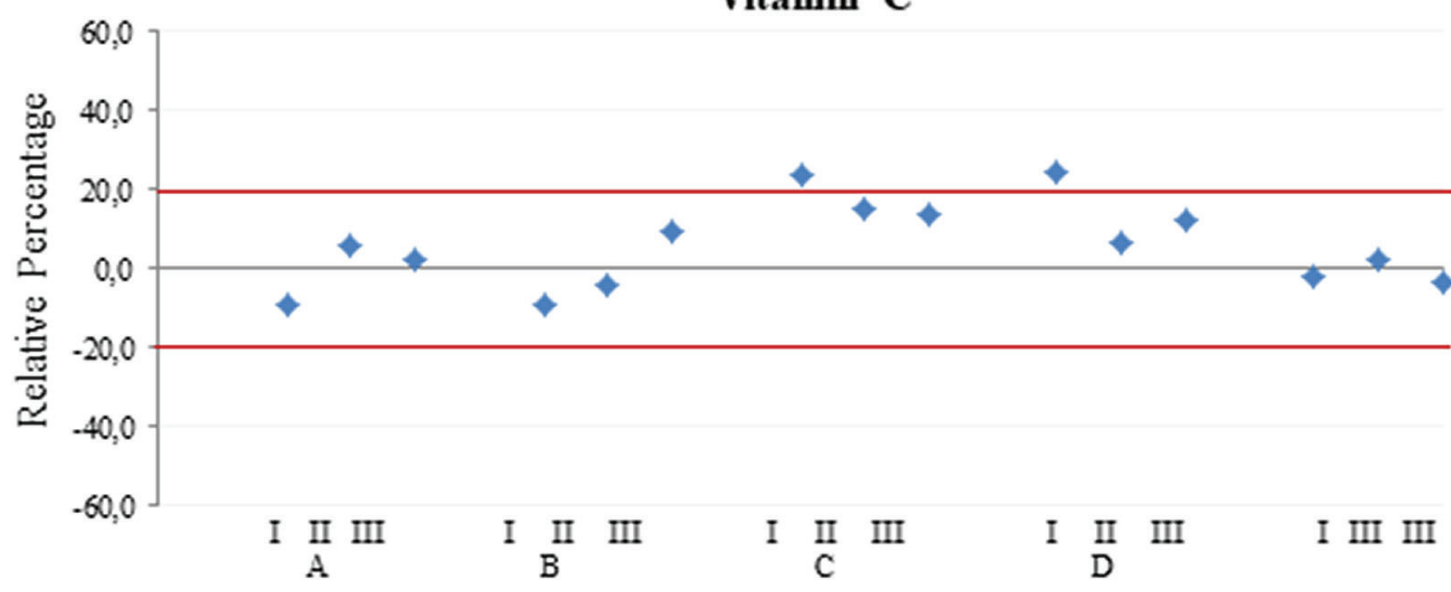

Samples

FIGURE 1 - Percentage of the relative variation of vitamins A, E, and C contents in the analyzed samples in relation to those declared on the label. Data in the area between red lines (-20 to 20): results in compliance with the legislation (i.e., samples whose difference between the analyzed and the declared value of vitamins are within the tolerance of $20 \%$ ). 
TABLE V - Number of months remaining until expiration date at the time of analysis

\begin{tabular}{cccccc}
\hline \multirow{2}{*}{ Batches } & \multicolumn{5}{c}{ Sample } \\
\cline { 2 - 6 } & A & B & C & D & E \\
\hline I & 11 & 14 & 15 & 20 & 8 \\
II & 10 & 11 & 19 & 23 & 5 \\
III & 11 & 15 & 9 & 17 & 12 \\
\hline
\end{tabular}

TABLE VI - Correlation* between the time in months remaining until expiration date and the values of vitamins determined at the time of analysis

\begin{tabular}{cccccc}
\hline \multirow{2}{*}{ Vitamins } & \multicolumn{5}{c}{ Samples } \\
\cline { 2 - 6 } & $\mathbf{A}$ & $\mathbf{B}$ & $\mathbf{C}$ & $\mathbf{D}$ & $\mathbf{E}$ \\
\hline A & 0,78 & 0,58 & 0,31 & 0,90 & 0,96 \\
E & $-0,25$ & - & $-0,43$ & 0,56 & 0,97 \\
C & $-0,65$ & 0,14 & 0,78 & $-0,68$ & 0,26 \\
\hline
\end{tabular}

* Pearson's linear correlation coefficients at 5\% probability level

of vitamins is necessary to maintain the stated contents during storage. However, the additional amount of vitamin required will depend on each sample, as beyond the respective matrix, several other factors related to the compounds and the packaging can also influence the stability of vitamins.

Different batches of supplements may or may not exhibit variations in the content of the vitamins studied, and these variations do not seem to be related solely to the time remaining until the expiration date. Three different batches of the same brand would or would not remain in compliance with the legislation, which is within the tolerance of $20 \%$ between the analyzed and the declared value of vitamins. Thus, in the evaluated samples, the differences in the vitamin contents observed between batches do not seem to be significant for inspection purposes. However, it is necessary to evaluate a larger number of samples for more conclusive results in relation to the variation in the vitamin content between batches.

Based on these results, the forms of presentation and packaging of the supplements, and the climate of the region where vitamin supplements are marketed, it is suggested that the shelf-life of these products be reviewed.

The application of microencapsulation technique, resistant packaging that protects from light, moisture, and oxygen, and adequate storage instructions on the labels are some of the suggestions to possibly decrease the degradation of vitamins in supplements. Additionally, there is a need for further studies on vitamin stability in supplements to establish the appropriate shelf-life period of each product.

\section{ACKNOWLEDGEMENTS}

We thank FAPESP for financial support [grant number 2013/23006-4].

\section{REFERENCES}

Abe-Matsumoto LT, Sampaio GR, Bastos D H M. Validação e aplicação de métodos cromatográficos para determinação de vitaminas em suplementos. Rev Inst Adolfo Lutz. 2016;75:1-14.

Brasil. Portaria n ${ }^{0} 32$, de 13 de janeiro de 1998. A Agência Nacional de Vigilância Sanitária aprova o regulamento técnico para fixação de identidade e qualidade de suplementos vitamínicos e ou de minerais. Brasília (DF): Ministério da Saúde, 1998. [citad 2017 Ago 7]. Available from: http://bit. ly/2vWS876.

Brasil. Resolução RDC n ${ }^{\circ} 259$, de 20 de setembro de 2002. A Agência Nacional de Vigilância Sanitária aprova o regulamento técnico sobre rotulagem de alimentos embalados. Brasília (DF): Ministério da Saúde, 2002. [citad 2017 Jun 15]. Available from: http://bit.ly/2f9NVd5.

Brasil. Resolução RDC nº 27, de 6 de agosto de 2010. A Agência Nacional de Vigilância Sanitária Dispõe sobre as categorias de alimentos e embalagens isentos e com obrigatoriedade de registro sanitário. Brasília (DF): Ministério da Saúde, 2010. [citad 2018 jan 20]. Available from: http://bit.ly/2nG31X1.

Codex Alimentarius - Codex Stan 1-1985 (Rev. 1-1991): Codex General Standard for the Labelling of Prepackaged Foods. 1991. [citad 2016 Oct 16]. Available from: http://www.fao.org/ docrep/005/y2770e/y2770e02.htm.

Equipe Estatcamp. Software Action. Estatcamp - Consultoria em estatística e qualidade. 2014. [citad 2017 Mar 20]. Disponível em: http://www.portalaction.combr.

Gregory J F. Vitamins. In: Damodaran S, Parkin K L, Fennema O R, editor. Fennema's Food Chemistry. 4th ed. Boca Raton: CRC Press; 2007. p. 439-522.

Haro-Vicente JF, Frontela-Saseta C, Romero F, Ros, G. Changes in content of vitamins $\mathrm{A}$ and $\mathrm{E}$ in growing-up milk throughout its shelf life. Int J Dairy Techno. 2012;65:1-6. 
International Alliance of Dietary/Food Supplement Associations. IADSA. Shelf-life recommendations for supplements. Guidelines for manufacturer. [citad 2017 Jan 20]. Available from: http://bit.ly/2h6fykm.

International Conference on Harmonization. ICH. Stability testing of new drug substances and products Q1A(R2). 2003. [citad 2018 jan 20]. Available from: http://www.ich.org/ fileadmin/Public_Web_Site/ICH_Products/Guidelines/Quality/ Q1A_R2/Step4/Q1A_R2_Guideline.pdf.

Melo ILP, Almeida-Muradian LB. Stability of antioxidants vitamins in bee pollens samples. Quím Nova. 2010;33(3):514-8.

Mercosul/GMC/RES. N²6/03 - Regulamento técnico Mercosul para rotulagem de alimentos embalados. 2003. [citad 2017 Sep 15]. Available from: http://bit.ly/2x4bEQy.
Phillips KM, Council-Troche M, Mcginty RC, Rasor AS, Tarrago-Trani MT. Stability of vitamin C in fruit and vegetable homogenates stored at different temperatures. J Food Comp Anal. 2016;45:147-62.

The United States Pharmacopeia. USP. 32nd. Rockville: The United States Pharmacopeial Convention; 2009. 3500p.

Tavcar-Kalcher G, Vengust A. Stability of vitamins in premixes. Animal Feed Sci Technol. 2007;132(1-2):148-54.

Received for publication on $26^{\text {th }}$ October 2017 Accepted for publication on $11^{\text {th }}$ February 2018 